\title{
Respiratory rate and severity of illness in babies under 6 months old
}

\author{
C J Morley, A J Thornton, M A Fowler, T J Cole, P H Hewson
}

\begin{abstract}
This paper defines the normal range of respiratory rate in babies under 6 months of age. It was counted by two observers in 1007 babies of whom 709 were seen when presenting to hospital for assessment of an acute illness, and 298 on a random basis at home. Whether they were asleep, content, or crying was recorded and the severity of their illness graded. The diagnosis was also recorded. The mean (SD) for the respiratory rate in babies seen awake was 61 (18) breaths/minute at hospital and 61 (14) breaths/minute at home. The respiratory rate when awake did not correlate with the severity of a baby's illness or the presence of serious lower respiratory tract infections. Sleeping babies had a significantly lower mean rate than awake babies at 42 (12) breaths/minute. Crying babies had a significantly lower mean rate than awake and content babies: 51 (14) breaths/minute compared with 61 (18) breaths/minute.
\end{abstract}

A high respiratory rate, or tachypnoea, is used as one of the most important signs of illness in infants. This is because lower respiratory tract infections are one of the major causes of morbidity and mortality in the first year of life. ${ }^{1}$ Surprisingly, a normal range for respiratory rate for healthy awake infants has not been published. The available data refers to babies who either were asleep most of the time ${ }^{2}$ or were seen in hospital. ${ }^{34}$ One of the reasons for a lack of normal data is that respiratory rate is difficult to count in healthy awake babies. Respiratory monitors can only be used to count respiration when the baby is asleep: when awake there is too much movement artefact for satisfactory interpretation of the respiratory signal. ${ }^{5}$ It is difficult to count respiration by observation because healthy awake babies breathe shallowly and irregularly, and their body movement masks many of the breaths. Because healthy babies are so obviously well it has probably not seemed important to quantify their respiratory rate. Without carefully collected data from healthy babies, however, it is not possible to define what is abnormal.

Several studies have advocated that in underdeveloped countries a respiratory rate above 50 breaths/minute can be used to help decide which infants should be given antibiotics. ${ }^{3} 4$ 6-8 Gove and Kumar stated that for acute respiratory illness control programmes aimed at improving infant survival from pneumonia, 'the accurate measurement of respiratory rate in a calm child is the most important clinical obser- vation in the detection of pneumonia' and 'for operational and training reasons, a single (and simple) threshold of $50 / \mathrm{min}$ for children less than 5 years, other than the newborn, may be appropriate for peripheral health workers with less training who examine children with a low prevalence of pneumonia'.

The sign of tachypnoea is taught as an important indicator of respiratory failure, ${ }^{10}$ bronchiolitis, pneumonia, or heart failure ${ }^{11}$ in infants. Surprisingly it is rarely defined.

This paper presents data on the normal respiratory rate and its variation in infants during the first six months of life from a two centre study designed to identify the markers of serious illness. ${ }^{12-14}$

\section{Subjects and methods}

One thousand and seven babies were assessed during one year. Each baby was seen by one of two assessors (PHH in Melbourne or AJT in Cambridge) who had practised the assessment together and worked from a detailed 35 page manual. A detailed history was taken and each baby examined carefully. The severity of each baby's illness was graded using several criteria: the assessor's impression of the baby's illness, the diagnosis, investigation results, and a review of the hospital notes by three independent paediatricians. The assessor's impression of the illness has been used as the best criteria for grading the illness because it was available for all babies, it was done at the time the baby was seen, and correlated very well with the other criteria. ${ }^{12}$

A pilot study showed that respiratory rate was difficult to count by observation in babies who were healthy and awake because they were so active and breathed shallowly and irregularly. We found that the best technique was to listen to breath sounds with a stethoscope or to put a warm hand gently on the baby's naked chest. The respiratory rate was counted three times for 15 seconds and averaged. If the baby was seen asleep the respiratory rate was counted and if the baby woke up it was counted again. The state of the baby at the time was categorised as: asleep, awake and content, awake and crying, awake and feeding, unconscious, or unknown. There were very few babies who were feeding or unconscious and they have not been analysed separately.

Of the 1007 babies assessed, 298 full term babies, chosen at random from the birth register, were seen at home in Cambridge. They were assessed on a predetermined date to ensure that they were seen evenly across the ages and 
seasons. The remaining 709 babies were seen when they were presented at hospital for assessment of an acute illness: 682 at the Royal Children's Hospital, Melbourne and 27 in Cambridge.

The assessor's illness categories contained the following number of infants: well $=290$, mildly ill $=305$, moderately ill $=247$, and seriously ill $=165$. The babies seen in hospital had a broad range of diagnoses. Of the 225 babies with respiratory infections, there were 78 with an upper respiratory tract infection and 13 with otitis media. Lower respiratory tract infection was recorded for 134 babies of which 74 were non-specific, six had pneumonia, 51 had bronchiolitis, and three had pertussis.

\section{Results}

The respiratory rate and other factors analysed in this paper were not recorded for every baby for technical reasons.

\section{LOCATION AND ASSESSOR}

The respiratory rate centiles for the babies who were awake and content at home in Cambridge and in hospital in Melbourne are shown in fig 1.

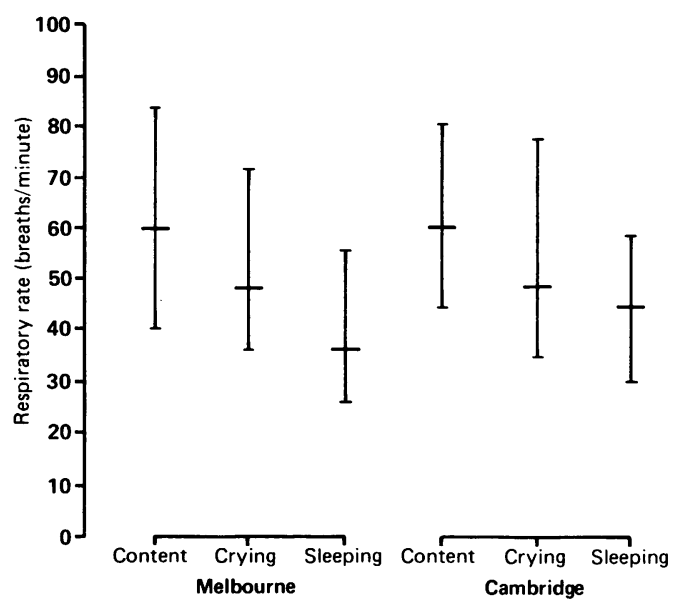

Figure 1 Respiratory rate centiles (10th and 90 th) in Cambridge and Melbourne.
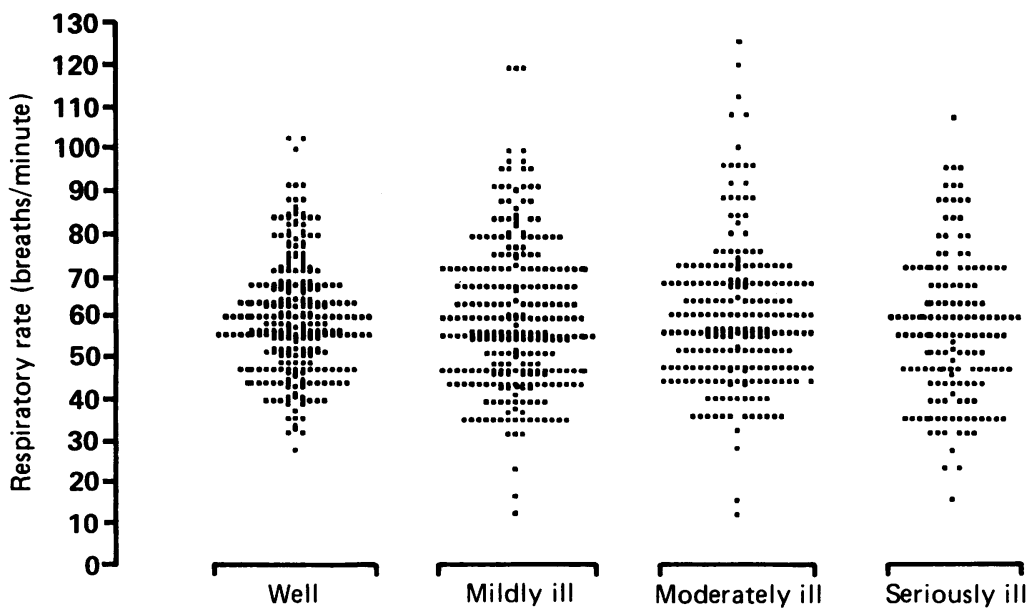

Figure 2 Respiratory rate of awake babies compared with assessor's impression of the severity of illness.
There was no difference in the mean (SD) respiratory rate recorded by the two assessors: Melbourne $(n=563) 61$ (18) breaths/minutes and Cambridge at home $(n=264) 61$ (14) breaths/minute.

\section{CONTENT OR CRYING}

The mean (SD) respiratory rate for the crying babies seen at home and in hospital was identical. The rate was significantly lower for babies who were crying $(n=108)$ at 51 (14) breaths/ minute than those who were awake and content $(\mathrm{n}=827)$ at $61(18)$ breaths/minute $(\mathrm{p}<0.0001)$.

SEVERITY OF THE ILLNESS

Figure 2 shows the individual respiratory rate of all awake babies compared with the assessor's impression of the severity of their illness. The mean (SD) for each group was: well $(n=280) 60$ (14) breaths/minute, mildly ill $(n=298) 61$ (18) breaths/minute, moderately ill $(n=244) 59(16)$ breaths/minute, and seriously ill $(n=153) 58$ (18) breaths/minute. Another eight babies who needed instant resuscitation are not included. There was no significant difference between the groups. The results are identical if the analysis is done only on babies presenting to hospital in Melbourne, or only for those babies who were awake and content.

\section{SLEEPING}

The respiratory rate was lower when babies were sleeping than when they were awake. There were 63 babies in the study whose respiratory rate was counted initially asleep and then when they woke up and settled. The mean (SD) for the respiratory rate increased from 42 (12) breaths/minute asleep to 56 (12) breaths/minute when awake $(p<0.0001)$.

SEX

Boys had a slightly higher mean (SD) respiratory rate when awake than the girls: boys $(n=537) \quad 61$ (17) breaths/minute and girls $(n=446) 58 \quad(15)$ breaths/minute $(p=0.032)$. There was no significant difference during sleep.

\section{A POSITIVE CHEST RADIOGRAPH}

There were 30 babies who had obvious changes of lower respiratory infection on chest radiography (evidence of consolidation or collapse in one or more segments). Their mean (SD) respiratory rate when awake was 65 (21) breaths/ minute compared with all the other babies, who either had a normal chest radiography or no radiograph taken $(n=953), 60$ (16) breaths/ minute $(p=0.055)$. Only one baby was asleep in this group.

\section{INFANTS WITH UPPER RESPIRATORY TRACT} INFECTIONS

Seventy eight babies had an upper respiratory tract infection. Their mean (SD) respiratory 
rate awake was 61 (18) breaths/minute. Four were seen asleep, their mean rate was 36 breaths/minute.

\section{INFANTS WITH LOWER RESPIRATORY TRACT INFECTIONS}

There were 134 infants with diagnosed lower respiratory tract infections. This included pneumonia, bronchiolitis, and non-specific lower respiratory tract infections. The mean (SD) respiratory rate when the babies were awake was 63 (17) breaths/minute. The 51 babies with bronchiolitis had the highest respiratory rate at 65 (16) breaths/minute. Only one of these babies was asleep. A regression analysis was used to see if any of the other factors shown in this paper were masking any association between lower respiratory tract infections and respiratory rate. It showed no significant association either awake or asleep.

RETRACTION OF THE CHEST WALL

In the babies counted awake there were 681 with no retractions, 257 with mild or slight retractions, and 37 with obvious or severe retractions. The mean $(\mathrm{SD})$ respiratory rate for these groups were $60(16), 60(17)$, and 65 (18) breaths/minute respectively. In the babies counted asleep there were 60 with no retractions, 13 with slight retractions, and one with obvious retractions. The rate for the first two groups were 42 (12) and 43 (8) breaths/minute.

\section{RECTAL TEMPERATURE}

There was a very poor correlation between rectal temperature and awake respiratory rate in both Melbourne $(r=0.06)$ and Cambridge $(r=0 \cdot 13)$. There was also little correlation between rectal temperature and sleeping respiratory rate.

\section{ENVIRONMENTAL TEMPERATURE}

There was little correlation between respiratory rate and environmental temperature $(r=0 \cdot 11)$.

\section{POSTNATAL AGE}

There was little effect of postnatal age on the awake respiratory rate. The numbers of babies at each month of age were: $134,220,169,184$ 141 , and 135 . The rate was not counted in 24 babies. The mean respiratory rate for each month was: $57,57,61,63,59$, and 59 breaths/ minute. The SD varied for each month between 14 and 18. Regression analysis taking into account the above factors showed a slight increase in respiratory rate with postnatal age $(p=0.04)$. The number of babies who were asleep during the assessment fell with age from 35 at 1 month to four at 6 months. The regression analysis showed no significant effect of age on sleeping respiratory rate.

\section{Discussion}

This paper has concentrated on the respiratory rate of babies at the time they were assessed to investigate its usefulness as a diagnostic tool in the clinic and admission room. In this situation most babies were awake.

These data, collected from predominantly white babies in developed countries, have shown that the median respiratory rate for awake infants without respiratory illness in the first six months of life is $\mathbf{5 8}$ breaths/minute with a 10th to 90 th centile range of 36 to 80 breaths/ minute. They have also shown that respiratory rate is not associated with the severity of an infant's illness or with respiratory infections or chest wall retraction. This is because the normal variation is so large in healthy babies. Even though babies with respiratory infections may have an average rate of 60 breaths/minute this is within the range for healthy babies. This suggests that respiratory rate cannot be used on its own to identify infants with lower respiratory tract infections.

Respiratory rate in infants is difficult to count and therefore prone to error. To count it as accurately as possible this study used the simple technique of listening through a stethoscope or placing a hand lightly on the chest. As the respiratory rates reported here are higher than have been previously suggested one has to ask whether there was a recording error. The most likely error would be to have missed some breaths so that the actual respiratory rate is more likely to have been higher than that recorded. The respiratory rate in this study was counted on large numbers of babies under different circumstances by two observers in different places. If the data are analysed for Melbourne alone the results are very similar (fig 1). The remarkable consistency in the results between the two centres adds robustness to the accuracy of the data.

Such a high respiratory rate in healthy infants is surprising and contrary to the accepted teaching. This may be due to several factors. Few people have carefully documented the respiratory rate in healthy awake infants; furthermore, most studies have concentrated on older babies. Those that have documented respiratory rate have either used sleeping respiratory rates or counted the rate by simple observation, a technique which is prone to under recording. ${ }^{4}$ Others may have only counted the respiratory rate in dyspnoeic infants and assumed that they must be tachypnoeic.

It is interesting and surprising that babies breathe so fast when awake. This may be because when awake they are very alert and tend to 'pant'. The slower respiratory rate found in sleeping babies is comparable with that reported when the rate had been counted with respiratory monitors. ${ }^{5}$ The babies with respiratory infection and obvious chest wall retraction were almost all awake at the time they were assessed so we cannot comment on the sleeping respiratory rate of such babies.

As the infant's state (content, crying, or sleeping) significantly affected the respiratory rate, future studies reporting respiratory rate in babies should record the state of the baby at the time the rate is counted.

This study only collected data from the first six months of life but our experience would 
suggest that babies throughout the first year of life breathe fast when awake.

At the start of this study it was confidently predicted that respiratory rate would be the best marker of serious illness, partly from our own observations and also from the literature. A respiratory rate above 50 breaths/minute has been recommended as an important sign of lower respiratory tract infection in infants and young children by the World Health Organisation and other groups interested in the early recognition and treatment of pneumonia. However, in this study approximately half the infants under 6 months had a respiratory rate above 50 breaths/minute. Therefore, on its own, this respiratory rate cut off cannot be used to distinguish accurately the severity of a baby's respiratory illness. The study of infants in the Gambia by Campbell et al has also shown that a respiratory rate above 50 breaths/minute was found in $68 \%$ of children without consolidation on their chest radiographs. ${ }^{6}$ They thought that a respiratory rate above 50 breaths/minute did not accurately predict pneumonia. In a study in Papua New Guinea, Shann et al showed that in infants under 1 year $27 \%$ of the babies without a cough had a respiratory rate of more than 50 breaths/minute. ${ }^{4}$

This study was not designed specifically to study respiratory rate in relation to pneumonia and, although there were 134 babies with lower respiratory tract infection and 30 with collapse or consolidation shown on chest radiography, only six were diagnosed as having pneumonia. It is therefore not possible to discuss the specific use of respiratory rate in the diagnosis of pneumonia except to make the general point that the variation in respiratory rate in well babies was so large that a high rate in pneumonia is unlikely to be outside the normal range.

This study, which has counted respiratory rate using a stethoscope or hand has shown that healthy infants in the first few months of life breathe faster than had previously been reported and that the large variation in rate is similar in both healthy and ill infants. On its own respiratory rate in awake infants is not very useful for differentiating the severity of an infant's illness. Combinations of other symptoms and signs such as reduced alertness, poor feeding, grunting expiration, and recession, however, can be used with considerable accuracy to indicate the severity of an infant's respiratory illness. ${ }^{15}$

We thank The Baby Illness Research Project Appeal for the Foundation for the Study of Infant Deaths, the Australian Institute of Health, the Ross Trust, Felton Bequests, the H L Hecht
Trust, the Percy Baxter Charitable Trust, and the A Williamss Trust, the Percy Baxter Charitable Trust, and the A Williamss
Private Fund. Dr D Roberton, Dr J McNamara, and Dr M Private Fund. Dr D Roberton, Dr J McNamara, and Dr M
Robinson reviewed the Melbourne case notes. Drs S Humphries, Robinson reviewed the Melbourne case notes. Drs S Humphries, (Cambridge) followed up the babies and kept the records.

1 World Health Organisation. A programme for controlling acute respiratory infections in children: memorandum from a WHO meeting. Bull WHO 1984;62:47-58. 2 Iliff $A$, Lee $V$. Pulse rate, respiratory rate, and body temper-
ature of children between two months and eighteen years of age. Child Dev 1952;23:237-45.

3 Cherian T, John T, Simoes E, Steinhoff M, John M. Evaluation of simple clinical signs for the diagnosis of acute respiratory tract infection. Lancet 1988;ii:125-8.

4 Shann F, Hart K, Thomas D. Acute lower respiratory tract infections in children: possible criteria for selection of patients for antibiotic therapy and hospital admission. Bull patients for antibiotic the

5 Richards J, Alexander J, Shinebourne E, de Swiet $M$, Wilson A, Southall D. Sequential 22-hour profiles of breathing $A$, Southall $D$. Sequential 22 -hour profiles of breathing
patterns and heart rate in 110 full-term infants during the patterns and heart rate in 110 full-term infants during
first six months of life. Pediatrics 1984;74:763-76.

6 Campbell H, Byass P, Lamont A, et al. Assessment of clinical criteria for identification of severe acute lower respiratory tract infections in children. Lancet 1989; i:297-9.

7 Campbell $\mathbf{H}$, Byass P, Greenwood B. Simple clinical signs for diagnosis of acute lower respiratory infections. Lancet 1988;ii:742-3.

8 World Health Organisation. Clinical management of acute respiratory infections in children: a WHO memorandum. Bull WHO 1981;59:707-16.

9 Gove S, Kumar V. Simple signs and acute respiratory infections. Lancet 1988;ii:626-7.

10 Gregory G, ed. Respiratory failure in the child. New York: Churchill Livingstone, 1981.

11 Kempe C, Silver H, O'Brien D, eds. Current pediatric diagnosis and treatment. Los Altos, California: Lange Medical Publications, 1982

12 Cole TJ, Morley CJ, Thornton AJ, Fowler MA, Hewson PH. A scoring system to quantify illness in babies under six A scoring system to quantify illness in babies under Six
months of age. Fournal of the Royal Statistical Society A (in months

13 Hewson PH, Humphries SM, Roberton DM, McNamara JM, Robinson MJ. Markers of serious illness in infants under 6 months old presenting to a children's hospital. Arch Dis Child 1990;65:750-6.

14 Thornton AJ, Morley CJ, Hewson PH, Cole TJ, Fowler MA, Tunnacliffe JM. Symptoms in 298 infants under six months old, seen at home. Arch Dis Child 1990;65:280-5.

15 Morley CJ, Thornton AJ, Cole TJ, Fowler MA, Hewson PH. Symptoms and signs in babies under 6 months of age correlated with the severity of their illness. Pediatrics (in press). 